\title{
Estudo de Sistemas Retardantes de Chama sem Bromo para ABS
}

\author{
Priscila Alves Martins, Ticiane Sanches Valera, Jorge Alberto Soares Tenório \\ Departamento de Engenharia de Materiais e Metalúrgica - PMT, Escola Politécnica - EP, \\ Universidade de São Paulo - USP
}

Resumo: Este trabalho visa estudar e caracterizar o desempenho de aditivos retardantes de chama não bromados em copolímero de ABS. Foram estudadas combinações de retardantes de chama, como: o polifosfato de amônio (APP), a melamina, nanopartículas de dióxido de titânio e argila organicamente modificada com sal quaternário de fosfônio. Os materiais obtidos foram caracterizados por ensaios mecânicos (resistência ao impacto Izod e resistência à tração), análise termogravimétrica (TG), avaliação da morfologia e ensaio de retardância à chama. Os resultados obtidos indicaram uma redução de cerca de $48 \%$ na velocidade de propagação da chama dos compósitos com APP $/ \mathrm{melamina} / \mathrm{TiO}_{2} / \operatorname{argila}$ organofílica, em relação ao copolímero de ABS puro.

Palavras-chave: Copolimero de ABS, retardantes de chama livres de bromo, nanopartículas de TiO ${ }_{2}$, argila organofilica, melamina, polifosfato de amônio.

\section{Flame Retardant Systems without Bromine for ABS Matrix}

Abstract: This work presents a study on alternative systems to substitute brominated flame retardants used in ABS. Combinations of flame retardants without bromine were studied: Ammonium polyphosphate, Melamine, Titanium dioxide Nanoparticles and phosphonium salt modified Organoclay. The composites obtained were characterized by mechanical tests (Izod Impact and Tensile strength), thermal analyses, scanning electron microscopy and Flame Retardancy tests. The results indicated that the Linear Burning Rate of ABS was reduced ca. $48 \%$ when the APP/MEL/OMMT/TiO 2 system was used.

Keywords: ABS copolymer, halogen free flame retardant, titanium dioxide nanoparticles, organoclay, melamine, ammonium polyphosphate.

\section{Introdução}

Polímeros ou misturas poliméricas utilizados em produtos eletroeletrônicos, no isolamento de fios e cabos, em produtos têxteis, automotivos ou aeronáuticos utilizam aditivos retardantes de chama para atender requisitos legais de níveis de segurança, pois estes aditivos reduzem ou inibem o processo de queima dos materiais poliméricos após o início da combustão. Um dos aditivos mais empregados são os retardantes de chama baseados em compostos bromados, como o óxido de decabromodifenila. Compostos bromados possuem mecanismo de ação retardante de chama muito eficiente. Os compostos bromados são aditivos que atuam quimicamente no processo de combustão, na fase gasosa. O composto sofre degradação térmica e produz radicais halogenados $(\mathrm{Br})$, que abstraem hidrogênios da cadeia polimérica, formando haletos de hidrogênio, $\mathrm{HBr}$, os quais rapidamente reagem com radicais como $\mathrm{H}$ e $\mathrm{OH}$, regenerando o radical $\mathrm{Br}$, que reage com hidrocarbonetos presentes na fase gasosa, regenerando o $\mathrm{HBr}$, e reiniciando o ciclo. Os radicais $\mathrm{He}$ $\mathrm{OH}$ são importantes para o processo de combustão, pois o H é responsável pela quebra das cadeias poliméricas via radical livre e $\mathrm{OH}$ é responsável pela oxidação do $\mathrm{CO}$ a
$\mathrm{CO}_{2}$ (reação altamente exotérmica, responsável por grande parte do calor gerado na queima do material polimérico). Portanto, a presença dos radicais halogenados diminui o potencial para propagação da combustão. Quando associados, sinergicamente, com compostos como trióxido de antimônio, mais radicais haologenados, $\mathrm{Br}$, são gerados na fase gasosa, e mais $\mathrm{H}$ e $\mathrm{OH}$ podem ser eliminados ${ }^{[1]}$.

Apesar de serem aditivos eficientes, os produtos da degradação dos compostos halogenados podem ser tóxicos, bioacumulativos e associados às doenças degenerativas ${ }^{[2]}$. Estudos recentes mostram que retardantes bromados contaminam os seres vivos e o meio ambiente ${ }^{[3]}$, durante a etapa de produção, o uso e/ou o descarte de componentes que o contenham. Os compostos bromados permanecem na natureza por um período indeterminando, tendo sido encontrados em: rios, lagos, na pele humana, na pele de animais e até mesmo em brinquedos infantis ${ }^{[4-6]}$.

Devido à preocupação com a saúde das pessoas e com a natureza, os retardantes de chama bromados receberam severas críticas. Na Europa foi criada uma legislação que restringe o seu uso, a diretiva RoHS ${ }^{[7]}$, e

Autor para correspondência: Priscila Alves Martins, Departamento de Engenharia de Materiais e Metalúrgica - PMT, Escola Politécnica - EP, Universidade de São Paulo - USP, Av. Professor Mello Moraes, 2463, Cidade Universitária, CEP 05508-030, São Paulo, SP, Brasil, e-mail: priscla@usp.br 
empresas localizados em países não europeus também vêm eliminando ou reduzindo, o uso destes aditivos.

Diante desse cenário, o presente trabalho apresenta um estudado sobre formulações de retardante de chama livres de bromo, que possam ser utilizados em matriz polimérica formada pelo copolímero de Acrilonitrila Butadieno Estireno (ABS). O ABS foi escolhido por representar o segundo polímero mais utilizado pela indústria de eletroeletrônico, que é a principal consumidora de retardantes de chama ${ }^{[8]}$.

\section{Experimental}

Nesse tópico é apresentada a metodologia de trabalho empregada. Primeiramente são mostrados os materiais estudados e em seguida o método de obtenção e caracterização.

\section{Materiais}

Os materiais utilizados neste trabalho foram: ABS GA800 fornecido pela Activas, nanopartículas de dióxido de titânio $\left(\mathrm{TiO}_{2}\right)$ P25 fornecidas pela Evonik Degussa, polifosfato de amônio (APP) da Clariant, melamina (MEL) fornecida pela Algicor, argila montmorilonita Cloisite Sódica, Cloisite $\mathrm{Na}^{+\oplus}$ da Southern Clay e o sal quaternário de Fosfônio, o Cloreto de Benzil Trifenil Fosfônio (ou BzTPPC) da Dishman. Os aditivos estudados foram comparados aos retardantes de chama comerciais formados por óxido de decabromodifenila e trióxido de antimônio, ambos fornecidos pela Chemtra.

\section{Método}

As amostras foram preparadas em extrusora dupla rosca Haake Modelo Rheomix PTW-16, acoplada a um Reômetro de torque ThermoHaake PolyLab 900. As condições de processamento dos compósitos durante a extrusão foram: temperatura de $230{ }^{\circ} \mathrm{C}$ e velocidade da rosca $120 \mathrm{rpm}$. Os compósitos foram obtidos com $25 \%$ em massa de carga e $75 \%$ em massa de ABS.

As condições de injeção foram: $220-230^{\circ} \mathrm{C}, 110$ bar de pressão de injeção, 85 bar de pressão de recalque, $12 \mathrm{~s}$ de temperatura de resfriamento, 30 bar de contrapressão e $60{ }^{\circ} \mathrm{C}$ de temperatura de molde. Foi utilizada uma injetora Demag Ergotech pro 35-115, diâmetro de rosca $25 \mathrm{~mm}$ e L/D 20. Foram injetados corpos de prova para ensaios de resistência à tração e ao impacto. As dimensões do corpo de prova para tração estão de acordo com a norma ASTM D $638^{[9]}$ e as do corpo de prova para impacto estão de acordo com a norma ASTM D256 ${ }^{[10]}$.

\section{Caracterização}

\section{Retardância à chama}

Os ensaios de retardância à chama foram baseados na norma ASTM D635 ${ }^{[11]}$ que sugere um valor quantitativo e qualitativo do desempenho dos aditivos ensaiados durante o processo de queima. Os parâmetros avaliados foram: velocidade de propagação da chama, ocorrência de gotejamento, combustão total dos corpos de prova, tempo de ensaio, distância percorrida da chama durante o ensaio. Os valores quantitativos representam médias dos corpos de prova ensaiados. Observação: o ensaio foi realizado em capela fechada, porém a capela não possui ambiente controlado, com vazão de gases constante.

\section{Ensaios mecânicos (resistência ao Impacto Izod e à Tração)}

Os ensaios de resistência ao Impacto Izod, sem entalhe, foram realizados em uma máquina Shanta Engineering Izod Impact (ensaio baseado na norma ASTM D256 ${ }^{[10]}$ ). Os ensaios de Tração foram realizados com velocidade de $2 \mathrm{~mm} / \mathrm{min}$, em uma Instron Modelo 3369 Universal (ensaio baseado na norma ASTM D638 $8^{[9]}$ ).

\section{Ensaios Térmicos (TG)}

As análises Termogravimétricas (TG) foram realizadas no equipamento Netzsch, Modelo STA 449 F1. As amostras foram aquecidas de $30^{\circ} \mathrm{C}$ até a temperatura de $1000^{\circ} \mathrm{C}$, com taxa de aquecimento de $10^{\circ} \mathrm{C} / \mathrm{min}$, em atmosfera de Nitrogênio, com fluxo de gás $50 \mathrm{ml} / \mathrm{min}$.

\section{Avaliação da morfologia}

A avaliação da morfologia foi realizada por Microscopia Eletrônica de Varredura (MEV), com detector EDS, utilizado para identificação (composição química) das cargas presentes na fase ABS. Foi utilizado equipamento MEV de marca Phillips, modelo XL-30 e equipamento MEV-FEG da marca FEI, modelo - Quanta 400F, Oxoford Instruments (IncaPenta FET $\times 3$ ). As micrografias apresentadas representam superfícies de fraturas de corpos de prova utilizados em ensaios de resistência à impacto, fraturados em nitrogênio líquido.

$\mathrm{O}$ ensaio de difração de raios- $\mathrm{X}$ foi utilizado para determinar o espaçamento basal das argilas, após o tratamento com sal de fosfônio (organofilização) e incorporação na fase polimérica. Foi utilizado um difratômetro de Raios-X modelo Xpert-MPD, marca Philips, com comprimento de onda de 1,540598 $\AA$. As amostras foram analisadas de $2 \mathrm{q}=1,01^{\circ}$ a $20^{\circ}$, a taxa de $0,02 \%$ min.

\section{Resultados e Discussão}

\section{Ensaio de Retardância à chama}

A Tabela 1 apresenta os resultados do ensaio de retardância à chama. Os seguintes parâmetros foram avaliados: velocidade média de propagação de chama, presença de gotejamento e a queima total do material durante o ensaio.

Os compósitos ABS/APP/MEL/TiO 2 e ABS/APP/MEL/ $\mathrm{OMMT} / \mathrm{TiO}_{2}$ obtidos exibiram redução na velocidade de propagação da chama, comparados ao copolímero ABS puro. O ABS puro apresenta gotejamento durante toda a etapa de queima, e atinge queima total. Os compósitos gotejam uma ou duas vezes em média, e extinguem a chama. Logo, não apresentam queima total.

Os compósitos exibiram comportamento diferente durante a propagação da chama. O compósito de ABS/APP/ 
$\mathrm{MEL} / \mathrm{TiO}_{2}$ apresentou extinção da chama após 20 segundos de ensaio, queimando apenas $10 \mathrm{~mm}$ do corpo de prova. $\mathrm{O}$ compósito ABS/APP/MEL/OMMT/TiO 2 queimou durante 109 segundos, consumindo $40 \mathrm{~mm}$ de corpo de prova.

O compósito halogenado $\mathrm{ABS} / \mathrm{DECA} / \mathrm{AO}$ não exibi gotejamento e nem queima total do corpo de prova, e a sua velocidade de propagação da chama não pode ser medida devido à extinção da chama durante o ensaio.

Destaca-se que, o compósito $\mathrm{ABS} / \mathrm{APP} / \mathrm{MEL} / \mathrm{TiO}_{2}$ não apresentou gotejamento e nem queima total, entretanto, foi observada uma redução de apenas $29 \%$ na velocidade de propagação da chama, quando comparada ao ABS puro. E apesar de apresentar gotejamento, a amostra ABS/APP/ $\mathrm{MEL} / \mathrm{OMMT} / \mathrm{TiO}_{2}$ mostrou uma velocidade de propagação de chama $48 \%$ menor do que a do ABS puro.

$\mathrm{O}$ mecanismo de retardância à chama observada em compostos com APP e melamina é conhecido como sistema intumescente, pois há formação de uma camada intumescida de resíduos carbonosos sobre a superfície do material polimérico que está queimando. A camada formada impede o fluxo de calor para a superfície do polímero e retarda a difusão de produtos voláteis da pirólise para a chama. Este mecanismo de ação é principalmente físico porque o próprio polímero não é necessariamente envolvido no processo de carbonização, mas a sua volatilização é retardada de forma significativa. As partículas de $\mathrm{TiO}_{2}$ e de argila podem ajudar no processo de formação de uma barreira física entre o oxigênio e a superfície do polímero que está queimando. Em particular, no caso das argilas, a decomposição de sal de fosfônio favorece a processo de intumescimento. Com a adição de argila Cloisite 10A e hidróxido de alumínio em matriz de poliestireno de alto impacto (HIPS), variando a concentração de carga entre $15 \%, 25 \%$ e $35 \%$ em massa, mediu-se redução de aproximadamente 54\% na velocidade de propagação de chama do HIPS. Observou-se que o sistema torna-se mais eficiente com o aumento da concentração de aditivos, porém o aumento da contração de aditivos implica em uma drástica redução nas propriedades mecânicas da fase matriz ${ }^{[12]}$.

\section{Ensaio mecânico de Resistência ao Impacto Izod}

Na Tabela 2 estão apresentados os valores médios da resistência ao Impacto Izod sem entalhe, do módulo de elasticidade e da resistência à tração para as todas as amostras estudadas.

Os resultados apresentados na Tabela 2 mostram que a adição de cargas na matriz polimérica de ABS implica em redução nos valores da resistência ao Impacto Izod sem entalhe. Os compósitos ABS/APP/MEL/TiO 2 e ABS/ APP/MEL/OMMT/TiO 2 apresentam as maiores reduções nos valores de resistência ao impacto, de 73\% e 87\%, respectivamente, em relação ao ABS puro.

A composição comercial ABS/DECA/AO mostrou redução nos valores de resistência ao impacto de $64 \%$ em relação ao ABS puro. O compósito $\mathrm{ABS} / \mathrm{APP} / \mathrm{MEL} / \mathrm{TiO}_{2}$ apresentou redução de $25 \%$ e o compósito ABS/APP/MEL/ OMMT/TiO 2 redução de $64 \%$ nos valores de resistência ao impacto, quando comparados com a amostra comercial.

Sohn et al. estudaram a blenda de PC/ABS e observaram redução máxima de $67 \%$ nos valores de resistência ao impacto Izod com a adição de 20 a $50 \%$ em massa de fosfareto de trifenil (TPP) ${ }^{[13]}$. Com o aumento da concentração de cargas (retardantes de chama) há uma diminuição nas propriedades mecânicas da fase matriz, uma vez que compósitos de matriz polimérica com cargas particuladas (com dimensões micrométricas) geralmente não apresentam melhorias em propriedades mecânicas, em relação à fase matriz, exceto em módulo de elasticidade ${ }^{[14]}$.

Os resultados mostram que o módulo de elasticidade para o ABS puro é de $1636 \pm 299 \mathrm{MPa}$. As amostras ABS/APP/ $\mathrm{MEL} / \mathrm{TiO}_{2}$ e ABS/APP/MEL/OMMT/TiO 2 apresentaram aumento nos valores de módulo de elasticidade, de $13 \%$ e $28 \%$ respectivamente, quando comparados ao $\mathrm{ABS}$ puro. $\mathrm{A}$ composição comercial ABS/DECA/AO mostrou aumento de $9 \%$ no valor do módulo de elasticidade, em relação ao ABS puro. Como já descrito, o aumento nos valores do módulo de elasticidade dos compósitos, em relação à fase matriz, são resultados esperados ${ }^{[14]}$.

No trabalho de Cui et al. foi observado maior aumento nos valores de módulo de elasticidade para compósitos com $20 \%$ de concentração de carga na matriz de HIPS. Quando um masterbacth de fósforo vermelho com nanopartículas de hidróxido de alumínio foi adicionado ao HIPS, os valores de módulo de elasticidade do compósito foram $44 \%$ maiores do que o obtido para o HIPS puro ${ }^{[15]}$.

Tabela 1. Ensaio de Retardância à chama baseados na ASTM D635.

\begin{tabular}{lccc}
\hline \multicolumn{1}{c}{ Composições } & Vel $(\mathbf{m m} / \mathbf{m i n})$ & Gotejamento & Queima total \\
\hline $\mathrm{ABS}$ Puro & 42 & Sim & Sim \\
$\mathrm{ABS} / \mathrm{APP} / \mathrm{MEL} / \mathrm{TiO}_{2}$ & 30 & Não & Não \\
$\mathrm{ABS} / \mathrm{APP} / \mathrm{MEL} / \mathrm{OMMT} / \mathrm{TiO}_{2}$ & 22 & $\mathrm{Sim}$ & Não \\
$\mathrm{ABS} / \mathrm{DECA} / \mathrm{AO}$ & Extinguiu & Não & Não \\
\hline
\end{tabular}

Polifosfato de amônio (APP), melamina (MEL), argila organofílica (OMMT), dióxido de titânio ( $\left.\mathrm{TiO}_{2}\right)$, óxido de decabromodifenila (DECA) e trióxido de antimônio (AO).

Tabela 2. Ensaio de resistência ao impacto Izod sem entalhe, módulo de elasticidade e Resistência à Tração. Considere o polifosfato de amônio (APP), melamina (MEL), argila organofílica (OMMT) e dióxido de titânio $\left(\mathrm{TiO}_{2}\right)$.

\begin{tabular}{lccc}
\hline \multicolumn{1}{c}{ Composições } & Resistência ao Impacto Izod $(\mathbf{J} / \mathbf{m})$ & Módulo de elasticidade (MPa) & Resistência à tração $(\mathbf{M P a})$ \\
\hline ABS PURO & $1284 \pm 226$ & $1636 \pm 299$ & $36,18 \pm 0,32$ \\
ABS/APP/MEL/TiO2 & $342 \pm 27$ & $1840 \pm 39$ & $25,97 \pm 0,15$ \\
ABS/APP/MEL/OMMT/TiO2 & $167 \pm 47$ & $2105 \pm 25$ & $26,45 \pm 0,64$ \\
ABS/DECA/AO & $458 \pm 39$ & $1782 \pm 47$ & $36,46 \pm 0,58$ \\
\hline
\end{tabular}


Isitman \& Kaynak estudaram poliestireno de alto impacto com a adição de hidróxido de alumínio e argila organofílica como retardantes de chama. Com respeito ao módulo de elasticidade foram observados aumentos de cerca de $120 \%$ para o nanocompósito com $25 \%$ de carga, em relação ao HIPS puro ${ }^{[12]}$. Os resultados de módulo de elasticidade dos compósitos estudados, ABS/APP/ $\mathrm{MEL} / \mathrm{TiO}_{2}$ e ABS/APP/MEL/OMMT/TiO , são inferiores aos obtidos por Isitman \& Kaynak, os quais estudaram concentrações mássicas de carga semelhantes às aqui avaliadas.

Os compósitos ABS/APP/MEL/TiO, e ABS/APP/ $\mathrm{MEL} / \mathrm{OMMT} / \mathrm{TiO}_{2}$ apresentaram redução nos valores de resistência à tração, de $28 \%$ e $25 \%$, respectivamente, quando comparados aos valores obtidos para o ABS. A redução no valor da resistência à tração foi observada em todos os compósitos produzidos, com exceção da composição comercial ABS/DECA/AO, em que a variação observada ficou dentro do desvio padrão, portanto, a resistência à tração se manteve constante para a amostra comercial.

O comportamento encontrado para os compósitos também foi observado por Isitman e Kaynak, que trabalharam com poli(metacrilato de metila) (PMMA) e os aditivos retardantes à chama argila organofílica, nanotubos de carbono e organofosforado comercial. O compósito com argila organofílica e o organofosforado apresentou redução de $22 \%$ no valor da resistência à tração, quando comparado ao da fase matriz ${ }^{[16]}$.

\section{Ensaio Térmico - TG}

A Tabela 3 apresenta os resultados relativos às temperaturas de decomposição dos compósitos ABS/APP/ $\mathrm{MEL} / \mathrm{TiO}_{2}$ e ABS/APP/MEL/OMMT/TiO ${ }_{2}$, juntamente com o compósito comercial e ABS puro. Os parâmetros estudados foram máxima temperatura de degradação (temperatura referente ao pico, presente na curva DTG) e a temperatura de decomposição térmica a $5 \%$ e a $50 \%$ de perda de massa.

A máxima temperatura de decomposição do copolímero ABS puro ocorreu a $413{ }^{\circ} \mathrm{C}$. A primeira etapa de decomposição do compósito $\mathrm{ABS} / \mathrm{APP} / \mathrm{MEL} / \mathrm{TiO}_{2}$ acontece a $345^{\circ} \mathrm{C}$ e para o compósito ABS/APP/MEL/OMMT/TiO a $351^{\circ} \mathrm{C}$. Essa etapa refere-se ao processo de decomposição dos aditivos presentes nas amostras.

A segunda etapa de decomposição observada nos compósitos é referente à decomposição do próprio ABS. Os compósitos obtidos apresentaram valores de máxima temperatura de degradação térmica equivalentes, variando em cerca de $7{ }^{\circ} \mathrm{C}$ em relação ao ABS puro. Os valores da temperatura de degradação térmica dos compósitos, com $50 \%$ de perda de massa também são semelhantes aos observados para o ABS puro.

O processo de decomposição do compósito do ABS puro resulta em $2 \%$ de massa residual, resíduo carbonoso, no final do ensaio, a $1000{ }^{\circ} \mathrm{C}$. A amostra ABS/APP/MEL/ $\mathrm{TiO}_{2}$ obteve $8 \%$ de massa residual referente ao resíduo carbonoso da decomposição do $\mathrm{ABS}$, resíduo do processo de fosforização do polifosfato de amônio e o dióxido de titânio.

O compósito ABS/APP/MEL/OMMT/TiO apresentou 9\% de resíduo referente aos resíduos carbonosos da decomposição do ABS, resíduos do processo de fosforização do polifosfato de amônio, do dióxido de titânio fica estável durante o ensaio, e resíduos da argila, que perdeu água e hidroxila estrutural, e pode até ter sofrido mudança de estado.

O processo de decomposição da amostra comercial ABS/DECA/AO ocorre em duas etapas, à primeira decomposição é referente à decomposição do decabromo, e a segunda decomposição é do próprio ABS.

Comparando a composição comercial com o ABS percebe-se que a decomposição ocorre em duas etapas, onde a primeira decomposição é referente à decomposição do decabromo com máxima temperatura de degradação térmica a $320{ }^{\circ} \mathrm{C}$, e a segunda é devido à decomposição do próprio $\mathrm{ABS}$ com máxima temperatura de degradação térmica a $417{ }^{\circ} \mathrm{C}$. A temperatura de máxima degradação do ABS manteve-se constante em todos os compósitos.

Os resultados das análises de termogravimétricas mostraram que os compósitos $\mathrm{ABS} / \mathrm{APP} / \mathrm{MEL} / \mathrm{TiO}_{2}$ e $\mathrm{ABS} / \mathrm{APP} / \mathrm{MEL} / \mathrm{OMMT} / \mathrm{TiO}_{2}$ apresentam duas etapas de decomposição, sendo a primeira uma antecipação do ABS e a segunda referente ao processo da sublimação da melamina.

\section{Avaliação da morfologia}

A Figura 1 apresenta a micrografia representativa da superfície de um corpo de prova de ABS puro (a esquerda em cima), composição ABS/APP/MEL/TiO 2 (a direita em cima) compósito ABS/APP/MEL/OMMT/TiO (esquerda embaixo) e a composição comercial ABS/DECA/AO (direita embaixo). As amostras foram todas fraturadas em nitrogênio líquido e realizadas análises de EDS nas regiões e pontos demarcados na Figura.

Tabela 3. Temperaturas de decomposição dos compósitos obtidos.

\begin{tabular}{|c|c|c|c|c|}
\hline Amostras & $1^{\circ}$ Pico $\left({ }^{\circ} \mathrm{C}\right)$ & $2^{\circ}$ Pico $\left({ }^{\circ} \mathrm{C}\right)$ & $5 \%$ de perda de massa $\left({ }^{\circ} \mathrm{C}\right)$ & $50 \%$ de perda de massa $\left({ }^{\circ} \mathrm{C}\right)$ \\
\hline ABS Puro & - & 413 & 375 & 420 \\
\hline $\mathrm{ABS} / \mathrm{APP} / \mathrm{MEL} / \mathrm{TiO}_{2}$ & 345 & 418 & 333 & 422 \\
\hline ABS/APP/MEL/OMMT/TiO ${ }_{2}$ & 351 & 420 & 320 & 425 \\
\hline $\mathrm{ABS} / \mathrm{DECA} / \mathrm{AO}$ & 320 & 417 & 315 & 408 \\
\hline
\end{tabular}

Polifosfato de amônio (APP), melamina (MEL), argila organofílica (OMMT), dióxido de titânio $\left(\mathrm{TiO}_{2}\right)$, óxido de decabromodifenila (DECA) e trióxido de antimônio (AO). 

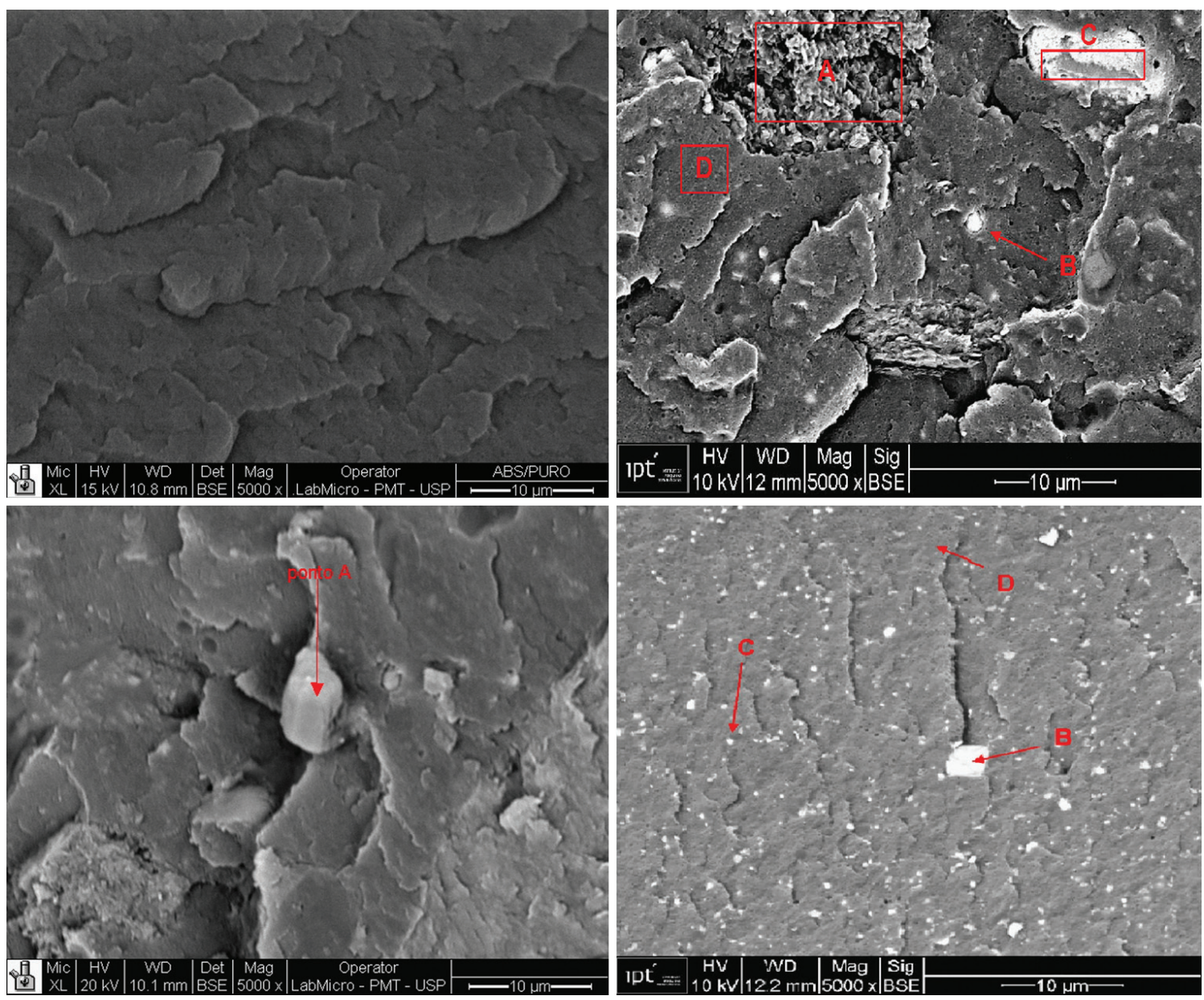

Figura 1. Micrografia do ABS puro (a esquerda em cima), da composição ABS/APP/MEL/TiO (a direita em cima), compósito ABS/ $\mathrm{APP} / \mathrm{MEL} / \mathrm{OMMT} / \mathrm{TiO}_{2}$ (esquerda embaixo) e a composição comercial ABS/DECA/AO (direita embaixo).

A micrografia referente ao compósito ABS/APP/MEL/ $\mathrm{TiO}_{2}$, apresenta uma região de rugosidade com predomínio de melamina (região A), porque a região A indica é rica em nitrogênio e a molécula de melamina apresenta $67 \%$ de nitrogênio ${ }^{[17]}$, conforme análise de EDS.

Partículas brilhantes estão dispersas na fase matriz do ABS. Parte dessas partículas se refere ao dióxido de titânio, ponto B, com partículas da ordem de $1 \mathrm{~mm}$, e outra parte, às partículas brilhantes e grosseiras da ordem de $14 \mathrm{~mm}$, se refere ao polifosfato de amônio, região C. A análise química das regiões $\mathrm{B}$ e $\mathrm{C}$, indicou a presença de Ti e $\mathrm{P}$, a cerca de $2-3 \%$ respectivamente.

A micrografia do compósito ABS/APP/MEL/OMMT/ $\mathrm{TiO}_{2}$ mostra a presença de partículas cinzas da ordem de $9 \mathrm{~mm}$ (ponto $\mathrm{A}$ ). A análise química da região $\mathrm{A}$, indica a presença de polifosfato de amônio e nanopartículas de dióxido de titânio. Nas demais regiões da amostra foram observadas uma mistura das cargas adicionadas à fase matriz, devido à presença dos elementos: $\mathrm{Mg}, \mathrm{Al}, \mathrm{Si}, \mathrm{P}$, Ti, O e N.

A micrografia do compósito comercial ABS/DECA/AO mostram partículas brilhantes e assimétricas com dimensões de cerca de $3,5 \mathrm{~mm}$, compostas predominantemente por óxido de decabromo com $15 \%$, como indicado pela análise química do ponto B, contra 1-2\% de trióxido de antimônio. Partículas brilhantes e assimétricas, com dimensões da ordem de $0,5 \mathrm{~mm}$, são formadas por uma mistura de cargas, trióxido de antimônio e decabromo, conforme a análise de EDS do ponto C.

A amostra comercial ABS/DECA/AO possui classificação V-0 na norma UL94 e as suas micrografias indicam uma morfologia com dispersão homogênea das partículas na fase matriz do ABS, com presença de aglomerados da ordem de $4 \mu \mathrm{m}$ (Figura 1 a direita embaixo).

As misturas com compostos livres de bromo apresentam uma distribuição não homogênea das cargas na fase matriz, com a presença de aglomerados micrométricos, maiores do que os observados no compósito comercial, apesar do uso de argilas do grupo esmectita e partículas nanométricas de dióxido de titânio como cargas retardantes de chama. A distribuição não homogênea das cargas livres de bromo na matriz de ABS e a presença de partículas grosseiras podem explicar a brusca queda em propriedades mecânicas dos compósitos.

\section{Análise de difração de raios- $X$}


A análise de difração de raios-X foi realizada para avaliar a microestrutura da argila organofílica no compósito $\mathrm{ABS} / \mathrm{APP} / \mathrm{MEL} / \mathrm{OMMT} / \mathrm{TiO}_{2}$.

A argila Cloisite sódica apresentou espaçamento interlamelar de 1,22nm. A argila Cloisite sódica seca possui espaçamento basal de $0,96 \mathrm{~nm}^{[18]}$. $\mathrm{O}$ aumento no valor de espaçamento basal de $0,26 \mathrm{~nm}$ deve-se a presença de água no espaço interlamelar.

A argila Cloisite sódica tratada com sal quaternário de fosfônio apresenta espaçamento interlamelar de $1,79 \mathrm{~nm}$, o que representa uma abertura de espaço interlamelar, em relação à argila sódica, de $0,57 \mathrm{~nm}$. O aumento do espaçamento basal da argila Cloisite evidencia a ocorrência de troca catiônica e a organofilização da mesma.

O compósito ABS/APP/MEL/OMMT/TiO, foi obtido com a argila organicamente modificada com o sal quaternário de fosfônio, e mostrou aumento no espaçamento interlamelar de $0,02 \mathrm{~nm}$, em relação à argila tratada. Esse pequeno aumento não indica que houve intercalação das lamelas de argila com a matriz polimérica, sugerindo, portanto, a formação de um microcompósito, como observado nas micrografias presente na Figura 1.

\section{Conclusão}

A adição de aditivos retardantes de chama livre de bromo em matriz de ABS implicou em redução na velocidade de propagação da chama, sendo que a amostra $\mathrm{ABS} / \mathrm{APP} / \mathrm{MEL} / \mathrm{OMMT} / \mathrm{TiO}_{2}$ apresentou redução da velocidade de propagação de $42 \mathrm{~mm} / \mathrm{min}$ para $22 \mathrm{~mm} / \mathrm{min}$, em relação ao copolímero de ABS.

$\mathrm{O}$ compósito $\mathrm{ABS} / \mathrm{APP} / \mathrm{MEL} / \mathrm{TiO}_{2}$ apresentou redução de $25 \%$ nos valores de resistência ao impacto Izod sem entalhe e o compósito ABS/APP/MEL/OMMT/TiO apresentou uma redução de $64 \%$, quando comparados com o compósito comercial ABS/DECA/AO.

Os compósitos ABS/APP/MEL/TiO 2 e ABS/APP/ $\mathrm{MEL} / \mathrm{OMMT} / \mathrm{TiO}_{2}$ apresentaram aumentos de $13 \%$ e $28 \%$, respectivamente, nos valores de módulo de elasticidade e redução de $28 \%$ e $25 \%$, respectivamente, nos valores de resistência à tração, quando comparados aos valores obtidos para o ABS.

A análise térmica de TG indicou que os compósitos possuem duas etapas de decomposição, uma referente à decomposição do polifosfato de amônio, a melamina e ao sal de fosfônio utilizado na argila organofílica, e uma segunda devido à degradação do próprio $\mathrm{ABS}$. O compósito comercial também possui duas etapas de decomposição, uma referente à decomposição do sistema óxido de decabromodifenila/trióxido de antimônio e outra devido ao próprio $\mathrm{ABS}$.

A morfologia dos compósitos estudados mostrou a presença de aglomerados e uma distribuição não homogênea das cargas, mesmo com o uso de nanopartículas de dióxido de titânio e da argila organofílica. Os resultados reportados poderiam ser melhorados caso uma dispersão mais homogênea e fina dos aditivos na fase dispersa fosse obtida.
O compósito comercial apresentou melhor distribuição das cargas na fase matriz e, consequentemente, melhores propriedades mecânicas do que os compósitos com adição de cargas livres de bromo.

A eficiência do sistema APP/melamina/carga inorgânica como retardante de chama para o ABS pode ser melhorada com o aumento da concentração de carga na fase matriz, porém este aumento traz como efeito colateral a queda em propriedades mecânicas do ABS, logo deve existir um compromisso entre desempenho mecânico e a propriedade de retardância à chama que um produto deve apresentar para se adequar a uma determinada aplicação.

\section{Agradecimentos}

Os agradecimentos desse trabalho se direcionam a CAPES pelo financiamento da bolsa de mestrado, a Escola Politécnica da Universidade de São Paulo pela disposição do espaço físico e equipamentos. As empresas: Activas, Chemtra, Evonik Degussa, Clariant e Agilcor pelo fornecido dos materiais.

\section{Referências Bibliográficas}

1. Gallo, J. B. \& Agnelli, J. A. M. - Polímeros, 8, p.23 (1998). http://dx.doi.org/10.1590/S0104-14281998000100005

2. Schecter, A.; Szabo, D.; Miller, J.; Gent, T.; Malik-Bass, N.; Petersen, M.; Paepke, O.; Colacino, J.; Hynan, L.; Harris, T.; Malla, S. \& Birnbaum, L. - Environ Health Perspect., 120, p.1 (2012).

3. Canaud, C.; Visconte, L. L. Y. \& Nunes, R. C. R. Polímeros, 11, p.35 (2011). http://dx.doi.org/10.1590/S010414282001000100009

4. Ali, N.; Harrad, S.; Muenhor, D.; Neels, H. \& Covaci, A. - Anal Bioanal Chem., 400, p.3073 (2011) PMid:21479791. http:// dx.doi.org/10.1007/s00216-011-4966-7

5. Skinner,L.-Environ. Pollut., 159,p.2565(2011). PMid:21742424. http://dx.doi.org/10.1016/j.envpol.2011.06.013

6. Takigami, H.; Suzuki, G.; Hirai, Y. \& Sakai, S. - Chemosphere, 76, p.270 (2009). PMid:19361833. http://dx.doi.org/10.1016/j. chemosphere.2009.03.006

7. European Union. "WEEE Directive 2002/96/EC", Official Journal of the European Union (2003).

8. Radian Corporation - "Chemical additives for the plastics industry: properties, applications, toxicologies", Noyes Publications, New Jersey (1987).

9. American Society for Testing and Materials - ASTM. "Standard test method for tensile properties of plastics", ASTM (2010) (ASTM D638).

10. American Society for Testing and Materials - ASTM. "Standard test methods for determining the izod pendulum impact resistance of plastics", ASTM (2010). (ASTM D256).

11. American Society for Testing and Materials - ASTM. "Standard test method for rate of burning and/or extent and time of burning of plastics in a horizontal position", ASTM (2010). (ASTM D635).

12. Isitman, N. A. \& Kaynak, C. - Polym. Degrad. Stab., 95, p.1759 (2010). http://dx.doi.org/10.1016/j. polymdegradstab.2010.05.012

13. Sohn, K.; Kim, M.; Lee, S.; Chu, B. \& Cho, K. - Fibers Polym., 12, p.451 (2011). http://dx.doi.org/10.1007/s12221011-0451-3 
14. Siqueira, B. G.; Visconte, L. L. Y.; Nunes, R. C. R.; Siqueira Filho, A. S. \& Gallo, J. - Polímeros, 11, p.89 (2001). http:// dx.doi.org/10.1590/S0104-14282001000200011

15. Cui, W.; Guo, F. \& Chen, J. - Fire Saf. J., 42, p.232 (2007). http://dx.doi.org/10.1016/j.firesaf.2006.11.002

16. Isitman, N. A. \& Kaynak, C. - Polym. Degrad. Stab., 95, p.1523 (2010) http://dx.doi.org/10.1016/j.polymdegradstab.2010.06.013
17. Morgan, A. B. \& Wilkie, C. A. - "Flame retardant polymer nanocomposites", John Wiley \& Sons, New Jersey (2007) http://dx.doi.org/10.1002/0470109033

18. Moore, D. M. \& Reynolds, R. C. - "X- ray diffraction and the identification and analisis of clay minerals", Oxford University Press, New York (1989).

Enviado: Maio 02, 2013 Reenviado: Mar. 21, 2014 Aceito: Abr. 16, 2014 